\title{
Spectroscopic Studies on Natural Gem- Agate in Sedimentary and Volcanic Host Rocks from (Bellesa, Addis Zemen and Bure), in Amhara National Regional State (Ethiopia)
}

\author{
Belaienesh Tesfa $^{1}$, Walelign Wubet ${ }^{2}$, Meselu Eskezia ${ }^{1^{*}}$ \\ ${ }^{1}$ Department of Chemistry, College of Natural and computational science, Oda Bultum University, Chiro, \\ Ethiopia \\ ${ }^{2}$ Department of Chemistry, College of Natural and computational science, University of Gondar, Gondar, \\ Ethiopia
}

*Corresponding Author: Meselu Eskezia, Department of Chemistry, College of Natural and computational science, Oda Bultum University, Chiro, Ethiopia

\begin{abstract}
The representative samples of gem-agate were collected from bellesa, addis zemen and bure. The samples were identified and characterized by different physical property measuring devices and advanced spectroscopic techniques. In order to verify that the samples were indeed agate a refractometer, heavy liquid method and "MOHS HARDNESS PENCILS" were used. The performed physical analysis shows that the hardness value of addis zemen and bure agate are in the range of 6.5-7 and that of bellesa agate is 7 while the refractive index and specific gravity of both agate samples are similar and in the range of 1.53-1.54 and 2.42.7 respectively. The XRD and FTIR spectral data of agate samples from three zones of the Amhara National Regional state have a significant contribution in their identification and characterization. The content of different trace elements ( $\mathrm{Ca}, \mathrm{Mg}, \mathrm{Fe}, \mathrm{Cu}, \mathrm{Cd}$ and $\mathrm{Mn}$ ) was analyzed by FAAS technique. Generally the investigated agate samples by using FT-IR show a broad band around 4000-2500 cm- 1 for the $O$ - $H$ stretch of water molecule, around $3585 \mathrm{~cm}-1$ structural defect of silanol group and around $1084 \mathrm{~cm}-1$ for Si-O stretch and at low frequency $694 \mathrm{~cm}-1$ indicates the $O-H$ stretch of silanol group. An agate yielded P-XRD pattern is characterized by four broad reflections, the sharp and most intense diffraction peak is pointed at $2 \theta=26.65^{\circ}$, medium intense sharp peak at $2 \theta=20.00 \mathrm{o}, 24.00 \mathrm{o}$ and 50.14o, broad peak at 20.83o and 68.85o and there is also weaker reflection band occur around $2 \theta=550$ and $64.00^{\circ}$. The XRD pattern for the three samples from three localities (Bellesa, Addis zemen and Bure agate, Ethiopia) are almost similar and comparable with the results obtained from the previous studies of agate in other countries (Australia, Morocco, India and Turkey).
\end{abstract}

Keywords: Gemstone; Agate; FTIR; XRD; FAAS; Ethiopia.

\section{INTRODUCTION}

In a recent history, mineral resources have a high priority in the Socio-economic development of the world. Naturally, Ethiopia is elegant and blessed with rich mineral resources. Its diverse geology comprises a variety of precious and semi-precious gemstone as well as industrial minerals resources, which offers a great opportunity for mineral prospecting and development [1]. Quartz is the most abundant silica mineral in the earth crust, found all over the world. The mineral potential of Ethiopia lies mainly with the development of gold, potash, thermal energies, and industrial minerals. Some industrial minerals found in Ethiopia are marble, granite, gemstone, limestone, clay, gypsum, iron ore, diatomite, coal, copper, silica etc... [2].

A gemstone is the naturally occurring crystalline form of a mineral which is desirable for its beauty, valuable in its rarity, and durable enough to be enjoyed for generations [4]. Gemstone exploration has recent history in Ethiopia. Quite a few studies were conducted by foreign experts, while limited explorations have been done by the ministry of mines besides energy and geological survey of Ethiopia. Gemstone's have higher economic value for the people who deals with it, not only the miners, but also the traders and designers [5].

Agates are spectacular products of nature, which have a cryptocrystalline structure formed from microscopic particles, mainly fibrous and partially granular silica particles and they are found all over 
Spectroscopic Studies on Natural Gem- Agate in Sedimentary and Volcanic Host Rocks from (Bellesa, Addis Zemen and Bure), in Amhara National Regional State (Ethiopia)

the world including: Asia, Brazil, Germany, India, Italy, Mexico, Nepal, many part of African countries and the USA of different geological environments. They are found in many parts of Ethiopia like Tigray (Adwa, Mekele and Aksum), northern Showa (MehaleMeda, Ankober, Sela Dingay, Jehur, Debre libanose and Yita Mechael), Wollo Kutaber and diverse geological part of Amhara national regional state $[6,7]$.

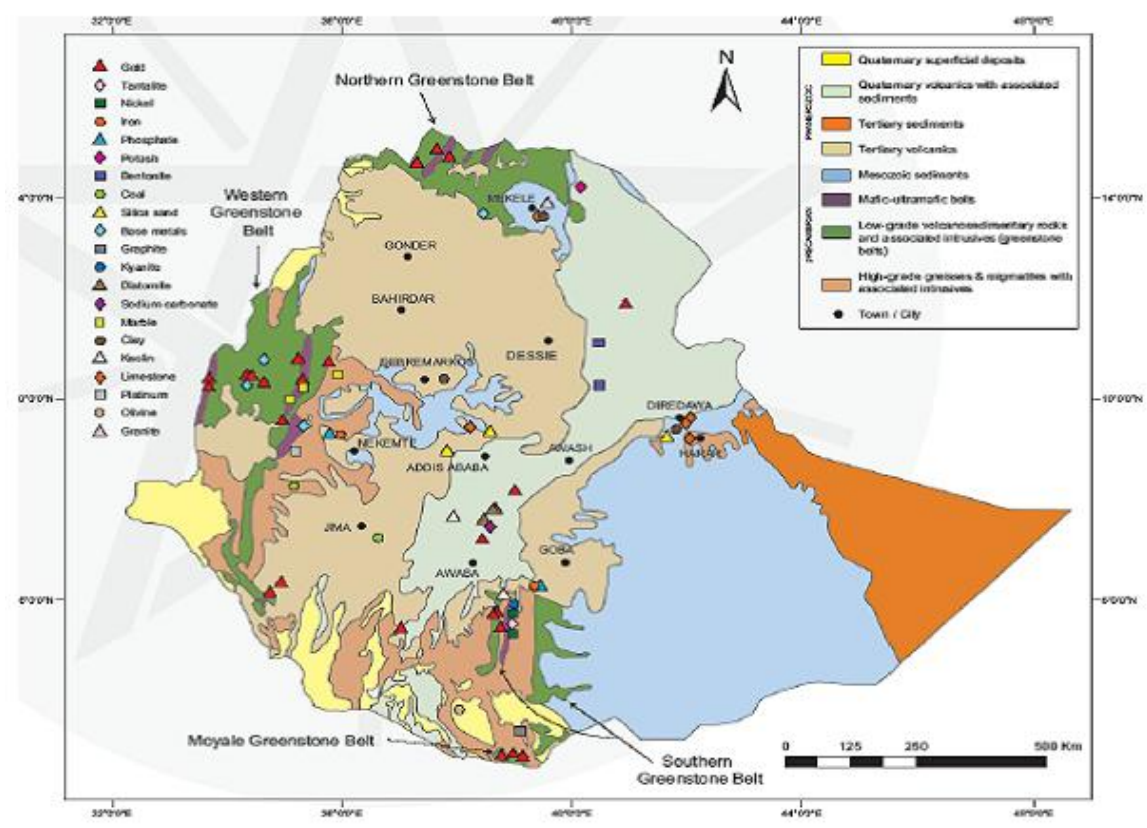

Figure1. key mining operations and mineral deposit in Ethiopia [3]

Agates are known a unique natural wonder for their amazing colors and different formation patterns, being widely used for jewelry and craft making, which is banded form of finely-grained, microcrystalline quartz. Despite their beauty and popularity, they are mainly composed by silica (a small molecule formed by only few atoms of silicon ( $\mathrm{Si}$ ) and oxygen $(\mathrm{O})$ ) with some sort of impurities [8].

Agate is a microcrystalline form of silica $\left(\mathrm{SiO}_{2}\right)$. It presents a chemical composition of around $97 \%$ of silica and less than $1 \%$ of non-volatile impurities. The concentration of impurity from $\mathrm{H}_{2} \mathrm{O}$ and $\mathrm{Si}-\mathrm{OH}$ is up to $2 \%$. Silica in agates is composed by two of its polymorphs: $\alpha$-quartz and up to $20 \%$ of moganite. In 1999, Zoetze et al., presents the structure of agate can probably be interpreted as alternating formation of fine-grained, highly defective chalcedony inter grown with moganite, and coarse-grained low-defect quartz [10].

To explain about how do agates form, several theories are settle down, but basically all of them state that agates form by the systemic deposition of silica in cavity walls generally resulting in banded patterns. The geochemical study demonstrated that the formation of agate can be a complex, multi-steps process. A very simple description of this process is that high temperature, pressure or ionized surface and magmatic waters are capable of dissolving the silica from the rocks where they pass through. When these water flow or evaporate, there is the formation of silica deposition [11].

$\mathrm{Mg}_{3} \mathrm{Si}_{2} \mathrm{O}(\mathrm{OH})_{4}+3 \mathrm{CO}_{2} \rightarrow 3 \mathrm{MgCO}_{3}+3 \mathrm{SiO}_{2}+\mathrm{H}_{2} \mathrm{O}$

These agates have banded crystal architecture with successive parallel layers to the side of cavities. These are the feature of cooling magma fluids in the form of bubbles of steam and other gases which overtake the process of solidification and are frozen in cavities. Later the fluid carrying alkali silicate percolates in to these bubbles and triggers coagulation and to become silica jell. Designers often take advantage of the intriguing patterns these stones have to offer to create unique and fascinating pieces [10].

Many agates form in areas of volcanic activity where, water rich in dissolved silica $\left(\mathrm{SiO}_{2}\right)$ flow through fractures and cavities in igneous rocks. When the solution is highly concentrated with dissolved silica, a silica gel can form on the walls of these cavities. That gel will slowly crystallize to form microcrystalline quartz. And also agates typically form in igneous rocks such as basalt, rhyolite, and andesite, they can also form in sedimentary rocks such as limestone [12]. 
Spectroscopic Studies on Natural Gem- Agate in Sedimentary and Volcanic Host Rocks from (Bellesa, Addis Zemen and Bure), in Amhara National Regional State (Ethiopia)

The spectroscopic techniques like Fourier Transform Infrared (FTIR), X-ray diffraction (XRD) and Flame Atomic Absorption Spectroscopy (FAAS) techniques were found to be useful scientific tools in identifying the natural gemstones. All of these techniques can perform the characterization or qualitative screening through elemental quantification of natural gem agate. It can be used to quantify the elements found in gem-agate as well as other materials that serve as evidence of certain treatment processes [30].

This paper presents the result of the application of some advanced analytical technique such as X-ray diffraction (XRD), and Fourier transform infrared (FTIR) spectroscopy for discrimination between natural gem agate hosted in Amhara national regional state (north Gondar, south Gondar and west Gojam) with the other natural gem agate studied by different researchers in different countries as well as various trace elements $(\mathrm{Ca}, \mathrm{Mg}, \mathrm{Fe}, \mathrm{Cu}, \mathrm{Cd}, \mathrm{Zn}$ and $\mathrm{Mn})$ in the sample is analyzed by flame atomic absorption spectrometry (FAAS). It would provide more information concerning the real structure of agate and characterize all genetic aspects of natural gem agate hosted in Amhara national regional state (Bellesa, Addis zemen and Bure).

The objective of this study is to identify and characterize natural gem-agate hosted in Amhara National Regional State of (Bellesa, Addis zemen and Bure agate), Ethiopia using spectroscopic techniques.

\section{Materials AND Methods}

\subsection{Instrumentation and Apparatus}

A refractometer of United Kingdom manufacture was used to measure the refractive index of agate with an optical contact liquid of $1.79 \pm 0.05$ at $25^{\circ} \mathrm{C}$. The specific gravity was measured using heavy liquid test (Lithium salt with specific gravity value 2.57 (UK)). Mohs Hardness Pencils (UK) was used to measure the hardness value of agate sample. A diamond pacific machine (UK Manufacture) was used to cut agate sample and a diamond paste machine (UK) was used to polish (clean) the agate sample. The ball mill grinder was used for grinding the agate sample. A sieve with $0.1 \mathrm{~mm}$ size was used to sieve powdered agate samples. An electronic digital balance (Denver instrument company USA) was used to weigh the powdered agate sample. Spectrum 65 FT-IR spectrometer (PerkinElmer instrument company U.S.A) was adjusted in transmittance mode and equipped with a $4 \mathrm{x}$ beam condenser with resolution $4 \mathrm{~cm}^{-1}$ and scanning speed auto $(16 \mathrm{~mm} / \mathrm{sec})$ in the wave length range of $400 \mathrm{~cm}^{-1}$ up to $4000 \mathrm{~cm}^{-1}$, was used for recording infrared transmission spectra of agate sample using $\mathrm{KBr}$ pellet method.

Miniflux 600 powder diffractometer (Rigaco instrument company, USA) equipped with CuKa radiation $(\lambda=1.5418 \AA)$ and a scan speed of $1 \%$ min and in the range between $10-70^{\circ} 2 \theta$ was used to collect Xray powder diffraction data for quantities and semi quantitative analyses of the mineral phase in the agate sample and host rocks.

Borosilicate Erlenmeyer flask and hot plate were used to digest the agate sample. Filter paper was used to distill the digested agate sample. The pipettes $(1 \mathrm{~mL}, 2 \mathrm{~mL}, 5 \mathrm{~mL}), 100 \mathrm{~mL}, 50 \mathrm{~mL}$ volumetric flask, $50 \mathrm{~mL}$ of Erlenmeyer flask and beakers were used to dilute the standards and samples' solution. An atomic absorption spectroscopy (BUCK SCIENTIFIC MODEL 210 VGP, U.S.A.) equipped with air/acetylene flame, with a hallow cathode lamp for the determination of Manganese, Cadmium, iron, calcium, zinc, copper and magnesium were used.

\subsection{Chemicals and Standard Solutions}

Chemicals that were used in the analysis are analytical grades. Deionized and distilled water was used for cleaning of glassware and for dilution of samples. Ethanol was used for washing the crystal sample after cutting. $\mathrm{KBr}$ (obtained in the PerkinElmer (U.S.A) accessories and consumable kit). $48 \%$ of $\mathrm{HF}$ (Anala R, PARK: Hydrofluoric acid Solution Northampton scientific Laboratory supplies, U.K), 6972\% (Analytical R, IMO: Nitric acid solution BDH Laboratory supplies, England) of $\mathrm{HNO}_{3}, 35.38 \%$ of $\mathrm{HCl}$ (Blulux, Laboratory reagent, Blulux Laboratories (p) LTD-121001), and 30\% of w/ $\mathrm{v}_{2} \mathrm{O}_{2}$ (MS Laboratory Reagent, Medical PVT.LTD, New Delhi) were used to digest the agate samples. Stock standard solution of the metals Ca $(1000 \mathrm{mg} / \mathrm{L}), \mathrm{Fe}(1000 \mathrm{mg} / \mathrm{L}), \mathrm{Mn}(1000 \mathrm{mg} / \mathrm{L}), \mathrm{Mg}(1000 \mathrm{mg} / \mathrm{L})$, $\mathrm{Zn}(1000 \mathrm{mg} / \mathrm{L}), \mathrm{Cd}(1000 \mathrm{mg} / \mathrm{L})$ and $\mathrm{Cu}(1000 \mathrm{mg} / \mathrm{L}))$ prepared for an atomic absorption spectrophotometer (BUCK SCIENTIFIC MODEL 210 VGP, U.S.A.) were used for the preparation of calibration curves for the determination of metals in the samples. 
Spectroscopic Studies on Natural Gem- Agate in Sedimentary and Volcanic Host Rocks from (Bellesa, Addis Zemen and Bure), in Amhara National Regional State (Ethiopia)

\subsection{Location and Accessibility of the Sample}

The samples were collected from Amhara national regional state particularly (Bellesa, Addis zemen and Bure. The research sites are situated at different latitudes, longitudes and elevations. Bellesa has a latitude and longitude of $13^{\circ} 12^{\prime} 35^{\prime \prime} \mathrm{N} 38^{\circ} 8^{\prime} 25^{\prime \prime} \mathrm{E}$, respectively and an elevation of 2133 meter above sea level), Addis Zemen (has a latitude and longitude of $12^{\circ} 07^{\prime} \mathrm{N} 37^{\circ} 47^{\prime} \mathrm{E}$, respectively and an elevation of 1975 meters above sea level) and Bure (has latitude and longitude $10^{\circ} 41^{\prime} 59.99^{\prime \prime} \mathrm{N} 37^{\circ} 03^{\prime} 60.00^{\prime \prime} \mathrm{E}$, respectively and elevation of 2091 meter above sea level).

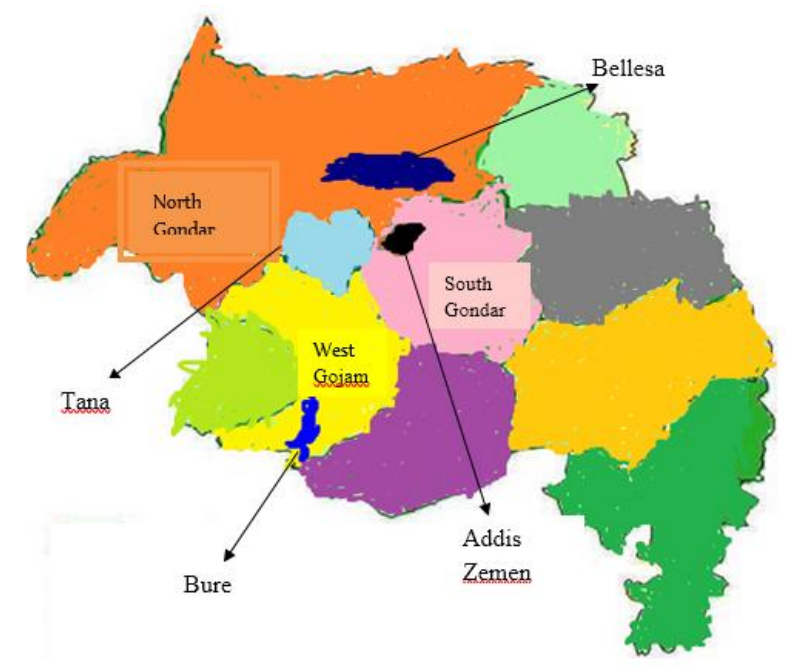

Figure2. Sample site location in the amhara national regional state, Ethiopia

\subsection{Collection of Agate Samples}

The agate samples were collected from the Polly technique colleges (Gondar, Debretabor and Bihar Dar) in cooperation with Administrative Zone Technical Vocational Enterprise Development Departments of South Gondar Zone, Debretabor; North Gondar Zone, Gondar and West Gojam Zone, Bahir Dar, and these three samples of natural gem agates were obtained from mining.

\subsection{Determination of Gemological Properties}

The physical properties of the samples were measured in order to verify that the samples are indeed agate or not. These gemological (non-destructive) characterization techniques were performed on representative samples. The physical measurements were performed at Gondar poly-technique College gemological testing laboratory, Gondar in Maraki branch. For these purpose a refractometer UK manufacture was used to measure refractive index (RI) with an optical contact liquid of $1.78 \pm 0.05 \mathrm{RI}$ at room temperature and the specific gravity was measured by heavy liquid method (Lithium salt)."The instruments of MOHS HARDNESS PENCILS" were used to determine the hardness values of agate samples

\subsection{Sample Preparation}

By following the procedure in below, the natural gem agate samples were washed with distilled water in order to remove surface contamination and dried in sunlight. The samples were cut with a diamond pacific machine and polished by a diamond paste. After that the samples were washed by distilled water, ethanol and dried in air and then grounded in to a fine powder by using ball mill grinder and sieved with a 0.1 sieve.

\subsubsection{Sample Preparation for FT-IR}

The FTIR analysis was carried out by taking powdered gem-agate samples exactly $2 \mathrm{mg}$ for each (measured using electronic digital balance) and mixed with $200 \mathrm{mg} \mathrm{KBr}$ in order to prepare circular pellet.

\subsubsection{Sample Preparation for XRD}

The XRD patterns analysis was carried out by taking powdered natural gem-agate samples and transferred it into sample holder of the instrument 
Spectroscopic Studies on Natural Gem- Agate in Sedimentary and Volcanic Host Rocks from (Bellesa, Addis Zemen and Bure), in Amhara National Regional State (Ethiopia)

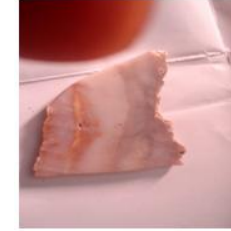

a)

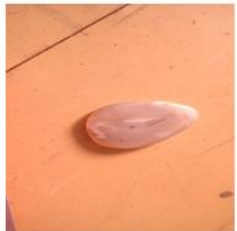

b)

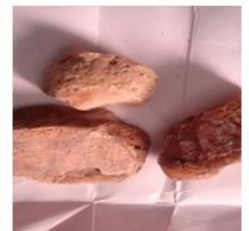

Figure3. The natural gem agate samples from (a) North Gondar, (b) South Gondar and (c) West Gojam.

\subsubsection{Sample Preparation for FAAS}

For FAAS analysis, from three powdered agate samples $(0.5 \mathrm{~g}$ each) was weighed and put in to three replicate $50 \mathrm{~mL}$ borosilicate glass of Erlenmeyer flask and $5 \mathrm{ml}$ conc. $69-72 \% \mathrm{HNO}_{3}, 2 \mathrm{ml} 35.5 \% \mathrm{HCl}$, $1 \mathrm{ml} 30 \% \mathrm{w} / \mathrm{v} \mathrm{H}_{2} \mathrm{O}_{2}$ and $2 \mathrm{~mL}$ of $48 \% \mathrm{HF}$ were added. Then after the Erlenmeyer flasks were heated on hot plate and the solution evaporated near dryness. After that $2 \mathrm{~mL} \mathrm{48 \%} \mathrm{HF} \mathrm{was} \mathrm{added} \mathrm{and} \mathrm{heated} \mathrm{for}$ a few times until precipitation of $\mathrm{SiO}_{2}$ is eliminated as $\mathrm{SiF}_{4}$ vapors. Cooling down to the room temperature, $2 \mathrm{~mL}$ conc. $\mathrm{HCl}$ and $5 \mathrm{~mL}$ of distilled water were added. Finally the solution was transferred in to $250 \mathrm{~mL}$ volumetric flasks and filled up with redistilled water up to the mark [34].

\subsection{Physical Measurements}

\subsubsection{Characterization Using FTIR}

Before the samples were run in the spectrum 65 FT/IR spectrometer PerkinElmer (U.S.A), the instrument's total inspection was done by measuring absorbance of the standard polystyrene film and empty sample compartment turn by turn. A background (KBr) measurement was done. Powdered FTIR spectra was collected at Addis Ababa University on 65 FT-IR PerkinElmer (U.S.A) spectrometer equipped with $\mathrm{KBr}$ beam splitter. Approximately $2 \mathrm{mg}$ of the sample was weighed using electronic balance and mixed with $\mathrm{KBr}$ powder (200mg for each sample).The mixtures were further powdered to mix well and then put in the instrument sample holder for solid sample analysis. Then each sample was examined by spectrum 65 FT/IR spectrometer PerkinElmer (U.S.A) operated at transmittance mode and resolution $4 \mathrm{~cm}^{-1}$ and scanning speed auto $(4 \mathrm{~mm} / \mathrm{sec})$ in the wavelength range of $400 \mathrm{~cm}^{-1}$ to $4000 \mathrm{~cm}^{-1}$.

\subsubsection{Characterization Using $X R D$}

To analyze, three gem-agate samples by using the modern analytical technique of (miniflux 600 powder $\mathrm{X}$-ray diffractometer) Rigaku instrument company U.S.A with rotating copper target of voltage 220v and current $15 \mathrm{~A}$, the fixed mass of powdered agate samples were weighed and transferred into the sample holder of the instrument.

The instrument was adjusted with $\mathrm{Cu}$ tube and a graphic monochromator with $\mathrm{CuK} \alpha$ radiation $(\lambda=$ $1.5418 \AA$ ) and a scan speed of $1 \% \mathrm{~min}$ in the range between $2 \theta=10-70^{\circ}$. The Powdered X-ray diffraction (XRD) experiment was performed at Addis Ababa University in Ethiopia.

\subsubsection{Trace Metal Determination Using FAAS}

To analyze the agate samples using the FAAS, the instrument were adjusted in appropriate manner such as, wave length selector; hallow cathode lamp, slit width, fuel valve and etc. The absorbance of the analytic line is a function of several parameters, burner head position (vertical, horizontal) and flow rate of used gases. Optimal values of these parameters are those, which yield maximum absorbance value. The optimization procedure was carried out by studying the effect of one parameter while keeping the others constants at appropriate values. To carry out this study the acetylene and airflow rate were kept constant. Before the samples were run in BUCK SCIENTIFIC MODEL 210 VGP, FAA spectrometer, the presence of precipitate in the sample as well as standard solution were refined and total inspection was done by measuring the absorbance of distilled water.

For the determination of metals in (Bellesa, Addis zemen and Bure agates, five series of standard metal solutions (Table-2) were prepared by diluting the standard solutions of the metal with distilled water. A blank (distilled water) and standards were run in flame atomic absorption spectrophotometer to establish five points of calibration curve. Each Sample solutions were aspirated into the FAAS instrument and direct readings of the metal absorbance were recorded. Three replicate determinations were carried out on each sample. The operating conditions of FAAS employed for each analyte are given below (Table 3). 
Spectroscopic Studies on Natural Gem- Agate in Sedimentary and Volcanic Host Rocks from (Bellesa, Addis Zemen and Bure), in Amhara National Regional State (Ethiopia)

Table2. Series of working standards for determination of metals in North Gondar, South Gondar and West Gojam agate varieties using flame atomic absorption spectrometer

\begin{tabular}{|c|c|c|c|}
\hline No & Element & $\begin{array}{c}\text { Concentration of } \\
\text { Standards }(\mu \mathrm{g} / \mathrm{ml})\end{array}$ & $\begin{array}{c}\text { Correlation } \\
\text { coefficient }(\mathrm{R})\end{array}$ \\
\hline 1. & $\mathrm{Ca}$ & $0.1,1,1.5,2,2.5$ & 0.808 \\
\hline 2. & $\mathrm{Zn}$ & $0.1,0.5,1,1.5,2$ & 0.946 \\
\hline 3. & $\mathrm{Mg}$ & $0.5,1,1.5,2,2.5$ & 0.958 \\
\hline 4. & $\mathrm{Mn}$ & $0.1,0.5,1,1.5,2$ & 0.919 \\
\hline 5. & $\mathrm{Fe}$ & $1,3,5,7,9$ & 0.960 \\
\hline 6. & $\mathrm{Cu}$ & $0.1,0.5,1,1.5,2.5$ & 0.991 \\
\hline 7. & $\mathrm{Cd}$ & $0.1,0.5,1,1.5,2$ & 0.997 \\
\hline
\end{tabular}

Table3. Instrumental operating conditions for determination of metals using (FAAS)

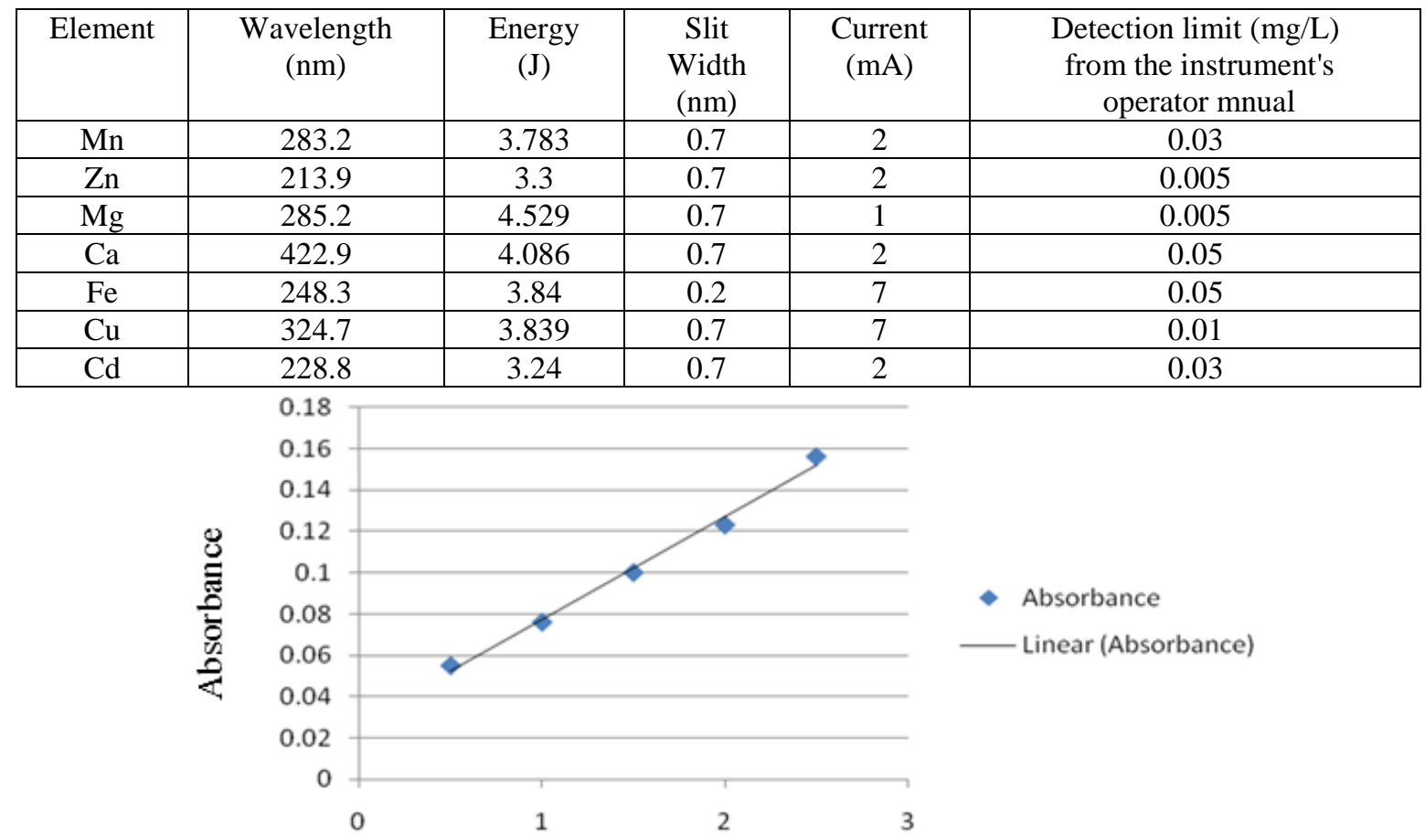

\section{Concentration}

Figure4. Calibration graph for calcium standard solution

$$
Y=0.049 x+0.027 ; R^{2}=0.992
$$

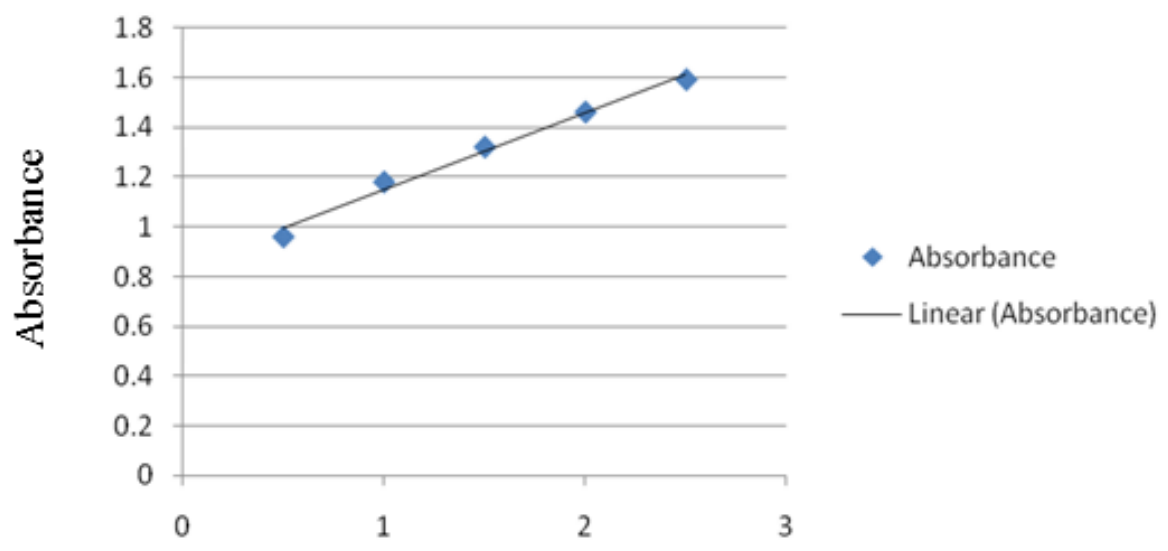

Concentration

Figure5. Calibration graph for magnesium standard solution

$$
Y=0.308 x+0.84 ; R^{2}=0.987
$$


Spectroscopic Studies on Natural Gem- Agate in Sedimentary and Volcanic Host Rocks from (Bellesa, Addis Zemen and Bure), in Amhara National Regional State (Ethiopia)

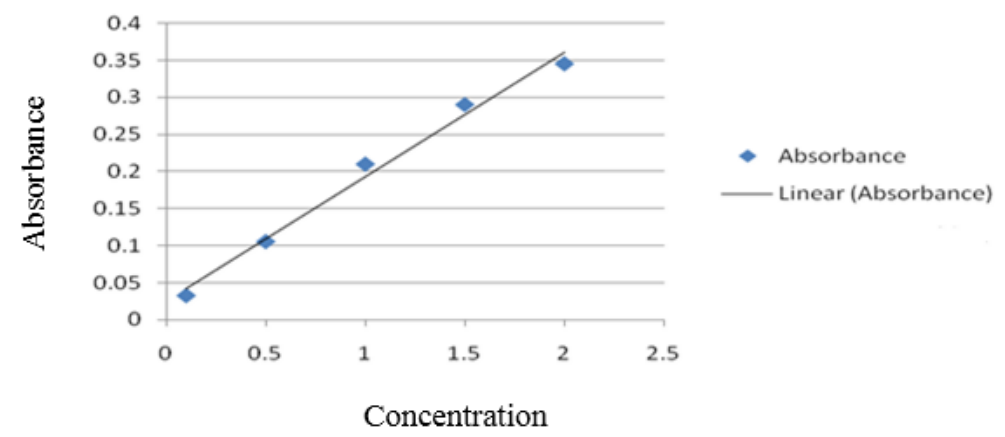

Figure6. Calibration graph for manganese standard solution

$$
Y=0.168 x+0.025 ; R^{2}=0.987
$$

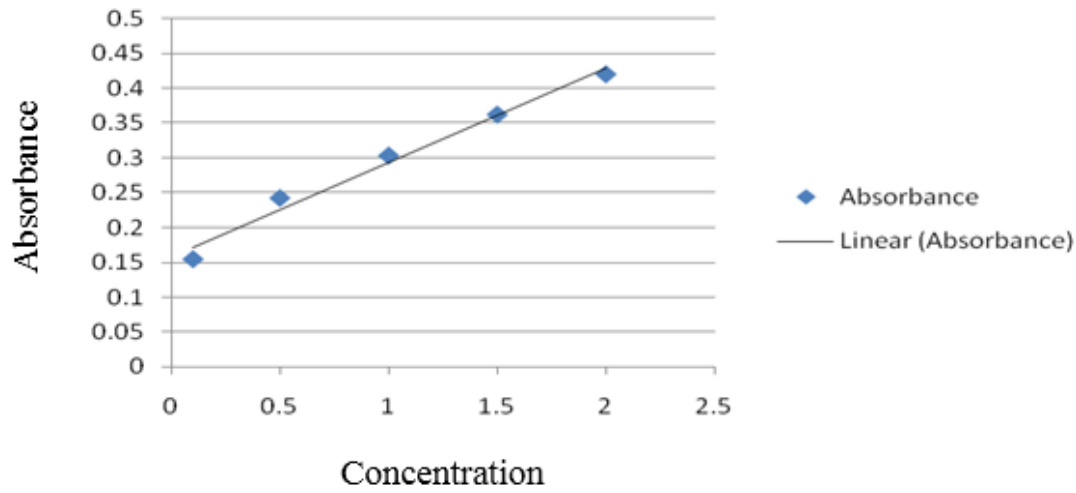

Figure7. Calibration graph for cupper standard solution

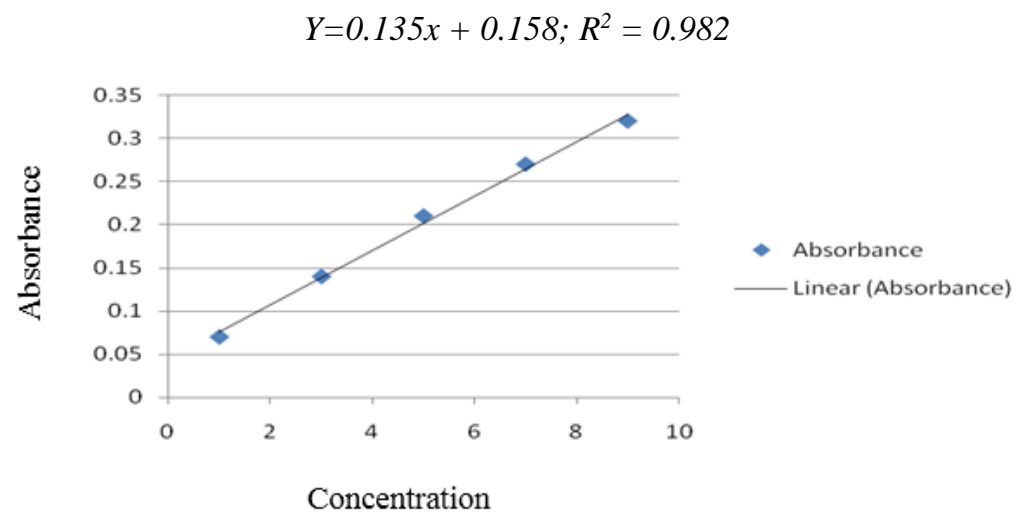

Figure7. Calibration graph for cupper standard solution

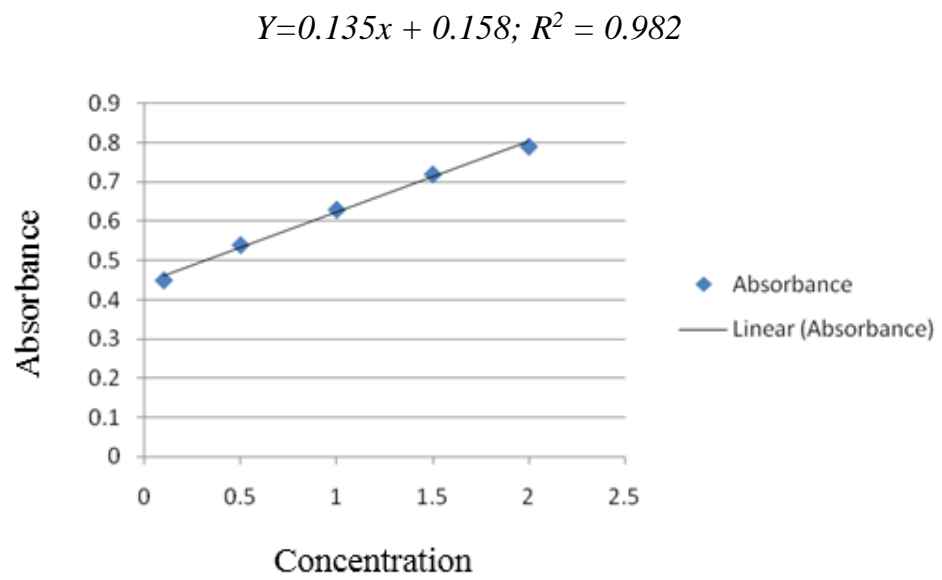

Figure9. Calibration graph for zinc standard solution

$$
Y=0.179 x+0.443 ; R^{2}=0.994
$$




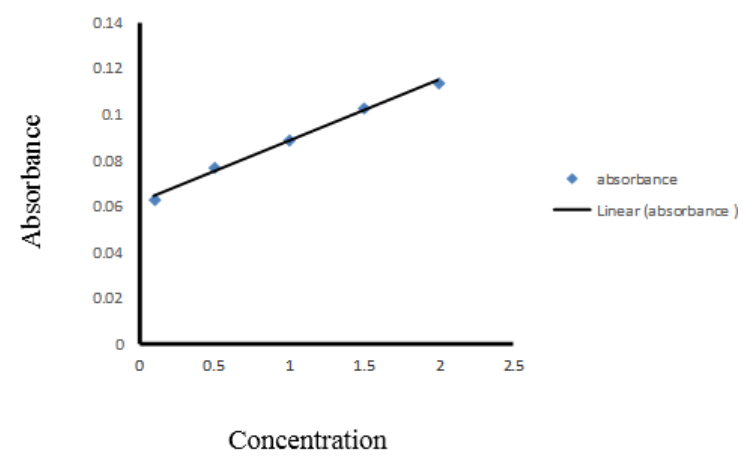

Figure10. Calibration graph for cadmium standard solution

$$
Y=0.0266 x+0.0621 ; R^{2}=0.995
$$

\section{RESULTS AND DISCUSSION}

\subsection{Gemological Properties}

To verify the investigated natural gem agate samples were indeed agate, non-destructive gemological characterization techniques were performed on representative samples. First, average specific gravity value of representative samples were measured by heavy liquid method using (Lithium salt). The results were within the range of 2.4-2.7. A similar result was observed in [24]. Because of optical character and optical sign, refractive index values of representative samples were determined by using standard refractometer device with an optical contact liquid of 1.79 RI. The refractive index values of the investigated samples were within the range of 1.53-1.54. Similar results were observed in [26].

"The "Mohs hardness pencils" were used to determine the hardness of gem-agate samples. This physical analysis shows that the hardness value of the addis zemen and bure agates are similar and they were within the range of 6.5-7 and that of bellesa is 7. Thomas Arter reported that the hardness values of agates are within the range of 6.5-7 [23]. The results of all these gemological testing values indicate that the samples were indeed agate samples.

\subsection{Infrared Spectroscopy Analysis}

Infrared spectroscopy is dependent on the response of short-range, molecular scale, energetic vibrations such as $\mathrm{O}-\mathrm{H}$ stretching and bending. This generates characteristic spectra for particular mineral phases depending on the molecules present, for example different water species. The vibration ranges of the hydroxyl $(\mathrm{OH})$ group water species, main silica mineral building components or inclusions, structural point defects, structural bonds, and coloration in silica can be determined using FT-IR spectrum in the mid-infrared region. Therefore, mid-infrared absorption spectroscopy is widely used to reveal the presence of water in gem and other mineral species. Meanwhile, the initial included waters in all mineral species can be divided into three groups, namely the hydroxyl $(\mathrm{OH})$ group located at structural defects, surface hydroxyls hydrogen bonded to each other $(\mathrm{H}-\mathrm{O}-\mathrm{H})$, and free molecular water $\left(\mathrm{H}_{2} \mathrm{O}\right)[14,33,34]$. The infrared spectra of (Bellesa, Addis zemen and Bure samples are presented in figures 10, 11, and 12 respectively.

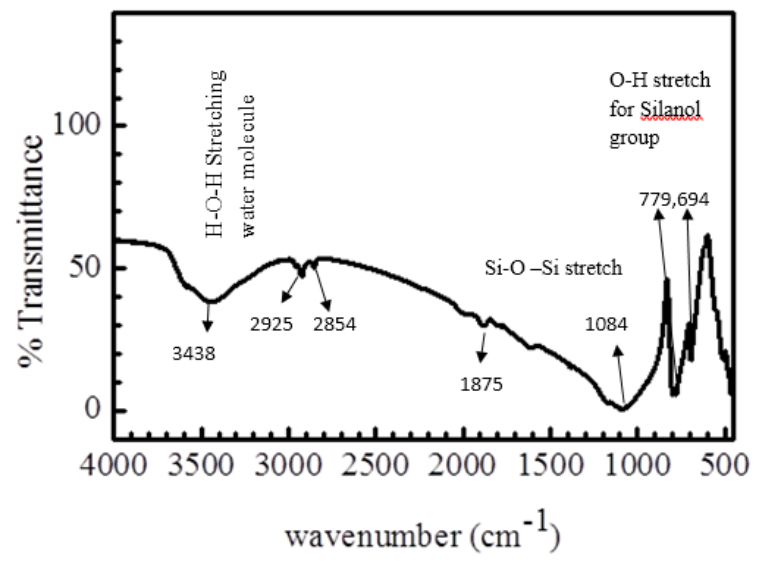

Figure11. The FT-IR spectrum of agate sample from bellesa 
Spectroscopic Studies on Natural Gem- Agate in Sedimentary and Volcanic Host Rocks from (Bellesa, Addis Zemen and Bure), in Amhara National Regional State (Ethiopia)

The FT-IR spectra of the investigated samples obtained from three different places ((Bellesa, Addis zemen and Bure) of Ethiopia were analyzed within the frequency region of 400 to $4000 \mathrm{~cm}^{-1}$ (Fig. 11, 12 and 13). The gross features of the FT IR absorption spectra of this three agate samples were similar. However, the absolute values of the absorption bands of bellesa $(694,779,1084,1736,1875,2854$, $2925,3421,3430,3433$ and $\left.3438 \mathrm{~cm}^{-1}\right)$ are distinctly different from those of addis zemen $(693,779$, $1086,1874,1877,1879,2718,3446$, and $\left.3576 \mathrm{~cm}^{-1}\right)$ as well as the bure $(694,797,1082,1687,1878$, 2924, 29633445 and $3586 \mathrm{~cm}^{-1}$ ). The FT-IR spectra of these three investigated agate samples were characterized by a multi component broad absorption bands centered around $3443 \mathrm{~cm}^{-1}$. This absorption band is related to the $\mathrm{OH}$ stretching and vibration in molecular water $\left(\mathrm{H}_{2} \mathrm{O}\right)$. Similar results were observed in $[14,33,34]$.

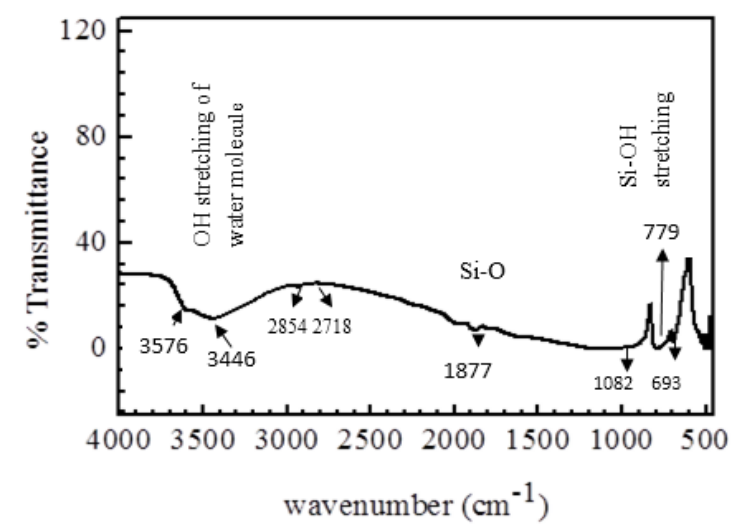

Figure12. The FTIR spectrum of agate sample from addis zemen

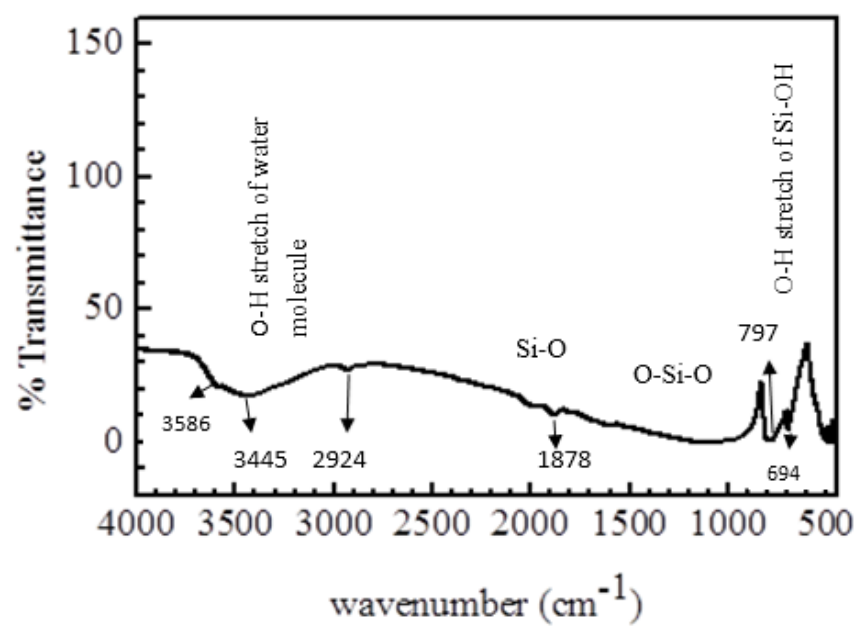

Figure13. The FTIR spectrum of agate sample from bure

According to the study conducted by Moxon T. et al. (2007) the sharp band present at approximately $3585-3590 \mathrm{~cm}^{-1}$ attributed to the structural defect of silanol (Si-OH) species. The FT-IR spectrum of bellesa didn't show shoulder around $3567 \mathrm{~cm}^{-1}$ and this indicate that the sample has no structural defect of the silanol group species but the addis zemen and bure sample show weak shoulder around 3576 and $3586 \mathrm{~cm}^{-1}$, respectively, indicating the presence of structural defects of silanol group [14,33].

In the low frequency region, from $1200 \mathrm{~cm}^{-1}-600 \mathrm{~cm}^{-1}$, the investigated samples have three bands centered around $694 \mathrm{~cm}^{-1}, 779 \mathrm{~cm}^{-1}$ and $1084 \mathrm{~cm}^{-1}$. These bands are due to the fundamental vibrations of $\mathrm{SiO}_{4}$ tetrahedral, related with $\mathrm{Si}-\mathrm{O}$ stretching vibration. There were similar observations in $[14,33$, $34,35]$. Particularly, the bands occur around $1080 \mathrm{~cm}^{-1}$ are assigned to asymmetric $\mathrm{Si}=\mathrm{O}=\mathrm{Si}$ stretching vibration and a band around $750-800 \mathrm{~cm}^{-1}$ is assigned to O-Si-O bending vibration, whereas the band centered near $694 \mathrm{~cm}^{-1}$ is assigned to $\mathrm{OH}$ stretching vibration. The observed data were comparable with literature data [34]. In these investigated samples, the percent transmittance value of (Bellesa, Addis zemen and Bure were almost around 60, 29 and 35\%, respectively. From this observation one can conclude that SGA absorbs the IR radiation higher than the other two and NGA is transparent to IR radiation in comparison with the other two. 
Spectroscopic Studies on Natural Gem- Agate in Sedimentary and Volcanic Host Rocks from (Bellesa, Addis Zemen and Bure), in Amhara National Regional State (Ethiopia)

Table4. Assignments of the Fourier transform infrared (FT-IR) bands of the gem-quality Agate from Amhara national regional state of Ethiopia

\begin{tabular}{|c|c|}
\hline $\mathrm{V}\left(\mathrm{cm}^{-1}\right)$ & Assignment \\
\hline Around 694 & OH stretch vibration's related to silanol \\
\hline $779-797$ & O-Si-O bending vibration \\
\hline $1082-1086$ & Asymmetric $\mathrm{Si}=\mathrm{O}=$ Si stretching \\
\hline Around 1687 & OH bending of water \\
\hline $1874-1878$ & Si-O bending vibration \\
\hline Around 2925 & Si-O stretching vibration \\
\hline $3421-3446$ & OH starching of water molecule \\
\hline 3586 & Si-OH structural defects \\
\hline
\end{tabular}

\subsection{Powder x-Ray Diffraction Analysis}

Gemological properties and mineralogical composition of natural gem-agate can be identified by different spectroscopic techniques. The mineralogical assemblage of host rocks could be determined by XRD pattern. An X-ray powder diffraction pattern was obtained for a sample of pure agate in three different zones of Amhara national regional state, Ethiopia (Fig. 14, 15 and16 below).

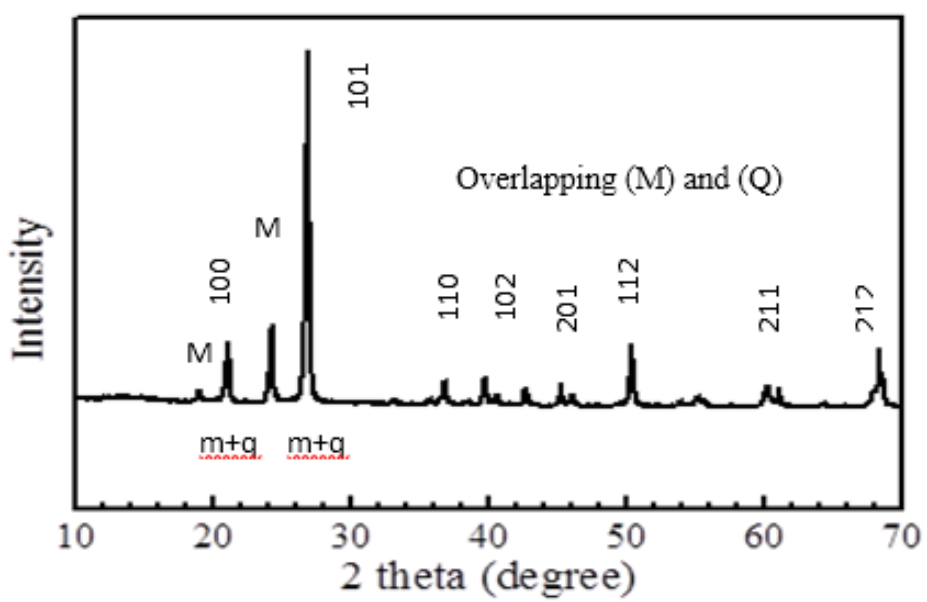

Figure14. X-ray diffraction patterns of alpha-Quartz $(Q)$ and Moganite $(M)$ of the (bellesa)

In this study, the investigated natural agate samples in the range between $10^{\circ}$ to $70^{\circ}$ show some resolved peaks at $2 \theta=20.85^{\circ}, 26.65^{\circ}, 36.54^{\circ}, 39.46^{\circ}, 42.47^{\circ}, 45.81^{\circ}, 50.14^{\circ}, 54.87^{\circ}, 59.95^{\circ}$ and $68.32^{\circ}$. According to the study conducted by Paral L. et al and Hatipoğlu M. et al. (2011) and Maoxon .T et al. (2008) on agate using XRD the same resolved peaks at the same $2 \theta$ values were observed. The numerical data obtained from XRD analyses of (Bellesa, Addis zemen and Bure samples were comparable with those studied natural agates of Australia and Turkey origin [14,32, 36].

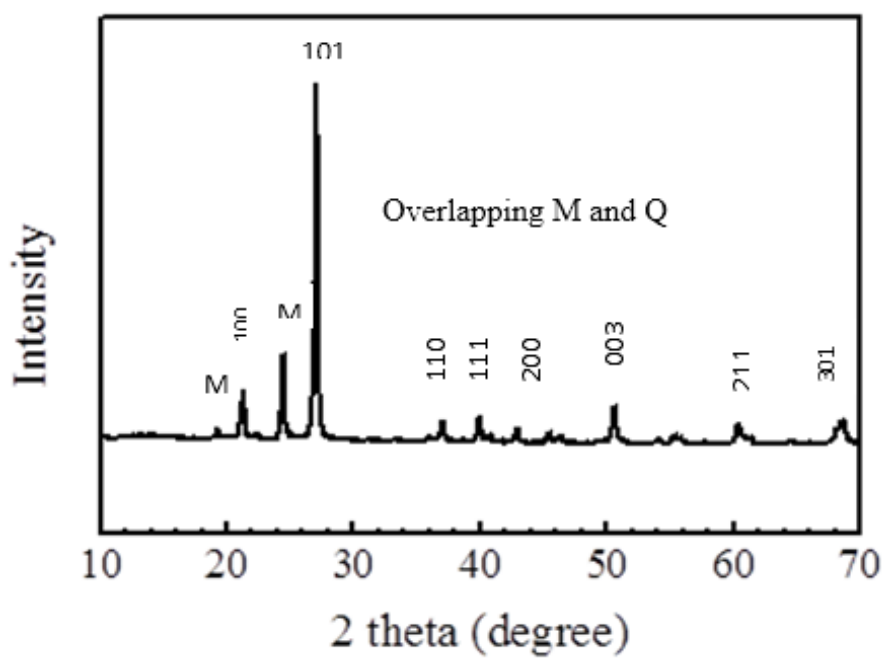

Figure15. X-ray diffraction patterns of alpha-Quartz $(Q)$ and Moganite $(M)$ of the addis zemen 
Spectroscopic Studies on Natural Gem- Agate in Sedimentary and Volcanic Host Rocks from (Bellesa, Addis Zemen and Bure), in Amhara National Regional State (Ethiopia)

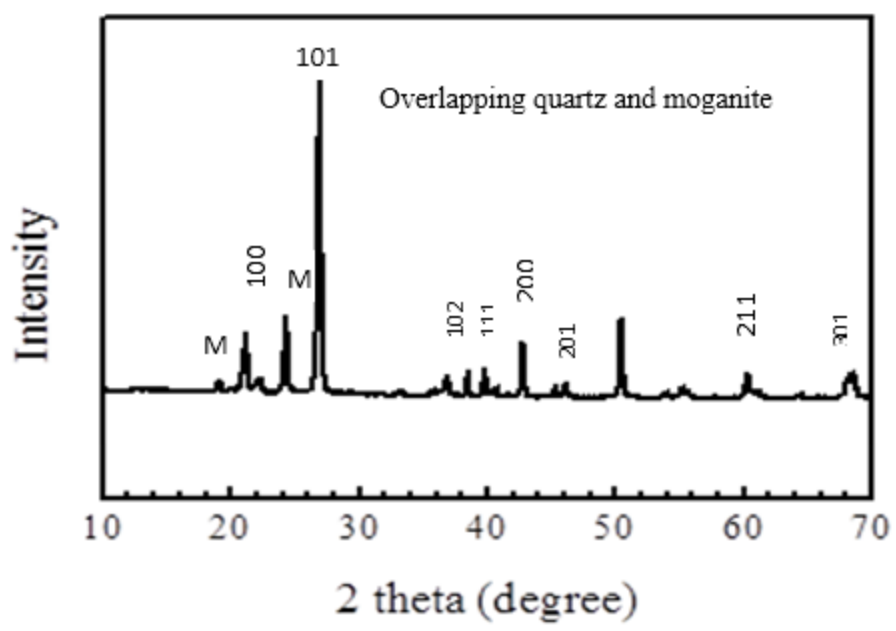

Figure16. X-ray diffraction pattern of alpha-Quartz $(Q)$ and Moganite $(M)$ of the bure

An agate yielded powder XRD pattern is characterized by four broad reflections, the sharp and most intense diffraction peak is pointed at $2 \theta=26.65^{\circ}-27.00^{\circ}$, medium intense sharp peak observed around $2 \theta=20.00^{\circ}, 24.00^{\circ}$ and $50.14^{\circ}$, broad peak at $2 \theta=20.83^{\circ}$ and $68.85^{\circ}$ and there is also weaker reflection band which occur at $2 \theta=55^{\circ}$ and $64.00^{\circ}$. By using XRD the same result were obtained in [14, 32, and 36]. A sharp intense peak indicates highly ordered, more crystalline than that of medium as well as weak peaks. The main and sharp peak occurred at $2 \theta=26.65^{\circ}$ indicating the degree of order in agate structure and the broad peak at $2 \theta=20.85^{\circ}, 36.54^{\circ}, 39.46^{\circ}, 42.47^{\circ}, 45.81^{\circ}, 50.14^{\circ}, 54.87^{\circ}, 59.95^{\circ}$ and $68.32^{\circ}$ indicates the presence of microcrystalline quartz building phases, such as cryptocrystalline alpha-quartz called chalcedony, cryptocrystalline quartzine (called moganite). This demonstrate that the moganite silica phases are present at $2 \theta=$ below $20^{\circ}$ and around $24^{\circ}$ and additionally in the overlapped diffraction bands. The observed XRD patterns of the investigated natural gem-agate samples are comparable with the literature and standard $\mathrm{x}$-ray diffraction powder pattern of silicon oxide (Quartzlow), $\alpha-\mathrm{SiO}_{2}$ in the table 5 below [36].

When we compare the peaks of the three samples (Bellesa, Addis zemen and Bure, sharp peak were observed in the bure sample. This demonstrates the bure sample is highly ordered crystalline than that of bellesa and addis zemen. The bellesa and addis zemen samples have similar peak intensity and this shows that the two samples have resemblance in crystalline order.

Table5. Standard x-ray diffraction powder pattern Silicon Oxide (Quartz-low), $\alpha-\mathrm{SiO}_{2}$ [CAS registry no. 7631 86-9]

\begin{tabular}{|c|c|c|c|}
\hline \multirow{2}{*}{$\begin{array}{c}\text { CuK } \alpha_{1} \\
\mathrm{~d}(\AA)\end{array}$} & \multicolumn{2}{|c|}{$\begin{array}{r}\lambda=1.540598 \AA \\
\text { Internal } \\
\text { standard } \mathrm{Si}\end{array}$} & $\begin{array}{r}\text { temp } 25 \pm 1^{\circ} \mathrm{c} \\
\alpha=5.43088 \AA\end{array}$ \\
\hline & $\mathrm{I}^{\mathrm{rel}} \quad \sigma= \pm 1$ & h k 1 & $2 \theta\left(^{\circ}\right)$ \\
\hline 4.257 & 22 & 100 & 20.85 \\
\hline 3.342 & 100 & $\begin{array}{lll}1 & 0 & 1 \\
\end{array}$ & 26.65 \\
\hline 2.457 & 8 & $\begin{array}{lll}1 & 1 & 0 \\
\end{array}$ & 36.54 \\
\hline 2.282 & 8 & 102 & 39.46 \\
\hline 2.237 & 4 & $\begin{array}{lll}1 & 1 & 1 \\
\end{array}$ & 40.29 \\
\hline 2.127 & 6 & $\begin{array}{lll}2 & 0 & 0 \\
\end{array}$ & 42.47 \\
\hline 1.9792 & 4 & $\begin{array}{|lll|}2 & 0 & 1 \\
\end{array}$ & 45.81 \\
\hline 1.8179 & 14 & $\begin{array}{lll}1 & 1 & 2 \\
\end{array}$ & 50.14 \\
\hline 1.8021 & $1 \mathrm{~L}$ & $\begin{array}{llll}0 & 0 & 3 \\
\end{array}$ & 50.61 \\
\hline 1.6719 & 4 & 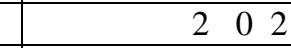 & 54.87 \\
\hline 1.6591 & 2 & 103 & 55.33 \\
\hline 1.6082 & $1 \mathrm{~L}$ & $\begin{array}{lll}2 & 1 & 0 \\
\end{array}$ & 57.24 \\
\hline 1.5418 & 9 & $\begin{array}{lll}2 & 1 & 1 \\
\end{array}$ & 59.95 \\
\hline 1.4536 & 1 & $\begin{array}{lll}1 & 1 & 3 \\
\end{array}$ & 64.00 \\
\hline 1.4189 & $1 \mathrm{~L}$ & $\begin{array}{lll}3 & 0 & 0 \\
\end{array}$ & 65.76 \\
\hline 1.3820 & 6 & $\begin{array}{lll}2 & 1 & 2 \\
\end{array}$ & 67.75 \\
\hline 1.3752 & 7 & $\begin{array}{lll}2 & 1 & 2 \\
\end{array}$ & 68.13 \\
\hline 1.3718 & 8 & $\begin{array}{lll}3 & 0 & 1 \\
\end{array}$ & 68.32 \\
\hline
\end{tabular}


Spectroscopic Studies on Natural Gem- Agate in Sedimentary and Volcanic Host Rocks from (Bellesa, Addis Zemen and Bure), in Amhara National Regional State (Ethiopia)

\subsection{Flame Atomic Absorption Spectroscopy Analysis}

The geochemical investigations of agates from their parent volcanic rocks and associated silicate mineralization represent an extensive analytical characterization of agates from localities around the world. Despite the different origin of the agate samples investigated, some common geochemical characteristics were observed. The trace element signature of most agate sample is characterized by FAAS. Concerning our study, we have characterized trace element signature of natural gem agate samples from bellesa, addis zemen and bure using FAAS. The results of the investigated samples are given in table 6 below.

Table6. The Mean concentration of trace element contents in natural gem agate sample

\begin{tabular}{|c|c|c|c|c|c|c|c|}
\hline Agate sample & \multicolumn{7}{|c|}{ Concentration of metal in mg/L(ppm) } \\
\hline Site & $\mathrm{Ca}$ & $\mathrm{Mg}$ & $\mathrm{Mn}$ & $\mathrm{Cu}$ & $\mathrm{Fe}$ & $\mathrm{Zn}$ & $\mathrm{Cd}$ \\
\hline bure & 0.247 & 0.349 & 0.011 & 0.004 & 0.199 & 0.001 & $\mathrm{Nd}$ \\
\hline bellesa & 0.357 & 0.293 & 0.016 & 0.015 & 0.389 & $\mathrm{Nd}$ & 0.002 \\
\hline Addis zemen & 0.057 & 0.275 & 0.037 & 0.009 & 0.208 & 0.001 & $\mathrm{Nd}$ \\
\hline
\end{tabular}

Figure17. Histogram comparing mean concentrations of metals in (bure, bellesa and addis zemen)

Trace element analyses of agates, quartz incrustations and associated parent volcanic rocks are carried out to obtain more information about the geochemistry of agates. Most trace elements show variations in their concentrations comparable to those seen in rock quartzes originating from different parent rocks. However, elevated concentrations were detected for those elements that are commonly contained within micro inclusions in the agate $(\mathrm{Cu}, \mathrm{Ca}, \mathrm{Fe}, \mathrm{Mn}$ and $\mathrm{Mg})$. They are frequently concentrated in colored agate bands, obviously acting as pigments [37]. In this study, the agate sample from bure and addis zemen have a high content of magnesium $(\mathrm{Mg})$ and less amount of copper $(\mathrm{Cu})$ whereas the agate sample of bellesa has the high content of iron $(\mathrm{Fe})$ and small amount of copper $(\mathrm{Cu})$. The color of agate is mainly associated with the presence of transition metals in its composition. The color of belessa agate is brown red associated with high Fe content, addis zemen agate and bure agate is a mixture of gray and white which is associated with high content of $\mathrm{Ca}$ and $\mathrm{Mg}$. The most common solid inclusions found within the agate matrix include pyroxene, calcium rich plagioclase, and goethite, and magnesite, $\mathrm{Mn}$ and $\mathrm{Cu}$ compounds [32].

\section{CONCLuSion}

The samples were characterized using physical property measuring devices (Refractometer, heavy liquid method and "MOHS HARDNESS PENCILS") and Spectroscopic Techniques (FAAS, XRD and FT-IR). The performed physical property measurement had confirmed the correct identity of the agate samples. The data obtained by measuring the agate samples using spectroscopic techniques were comparable with studies conducted in different countries by different researchers. The performed physical analysis showed that the hardness value of bure agate and addis zemen agate are within the range of 6.5-7 and that of bellesa agate is 7 (slightly harder than that of bellesa agate and bure agate ) but the refractive index and specific gravity of these investigated samples have similar value i.e., in between 1.53-1.54 and 2.4-2.7 respectively. The crystal structure were estimated using XRD studies, trace and minor elements were determined using FAAS, and the major compositional elements and water contents were confirmed by FT-IR studies. Using the FAAS Spectroscopic technique, seven elements $(\mathrm{Ca}, \mathrm{Mg}, \mathrm{Cd}, \mathrm{Cu}, \mathrm{Fe}, \mathrm{Mn}$, and $\mathrm{Zn})$ were measured. The FAAS result showed that the intensity of orange color (from yellow to orange to red to "chocolate"- brown) correlates with the large amount 
Spectroscopic Studies on Natural Gem- Agate in Sedimentary and Volcanic Host Rocks from (Bellesa, Addis Zemen and Bure), in Amhara National Regional State (Ethiopia)

of Fe concentration and white color correlate with large amount of $\mathrm{Ca}$ concentration in the agate samples. It is also presented that the FT-IR spectroscopy could not discriminate between the difference color varieties of the studied agate samples. However, the presented FT-IR spectra data for agate samples have a significant contribution in their identification and characterization. This spectroscopic technique is important to identify their functional group in the agate formation. XRD patterns were used to determine mineralogical assemblage of host rocks. It helped to classify the base silica building components in to moganite, quartz and chalcedony

\section{ACKNOWLEDGEMENT}

The authors are grateful to Department of Chemistry, University of Gondar, for providing laboratory facilities and materials throughout my study and we would like to thank Debretabor Polytechnique College, Bahir Dar Polytechnique College, Bahir Dar for the kind donation of the natural gem agate samples.

\section{REFERENCES}

[1] Weissleder Lucie. "Foreign direct investment in the agricultural sector in Ethiopia." University of Bonn (2009).

[2] Assefa Getaneh. "The mineral industry of Ethiopia: present conditions and future prospects." African Earth Sciences 3, 3 (1985) 331-345.

[3] Abay. "UK-Ethiopia Investment Trade and Tourism Forum." Investment Opportunities in the Mining Sector of Ethiopia (2011).

[4] Moxon, T., S. J. B. Reed, and M. Zhang. "Metamorphic effects on agate found near the Shap granite, Cumbria, England: as demonstrated by petrography, X-ray diffraction and spectroscopic methods." Mineralogical Magazine 71, 4 (2007) 461-476.

[5] Hundie Melka. Geology and Mineral resources of Ethiopia." Forum of Mining Investment in Ethiopia (2016)

[6] Wondafrash. Opportunities for Gem resource development in Ethiopia, ministry of mine and energy (2009)

[7] Richter, S., J. Götze, H. Niemeyer, and R. Möckel. "Mineralogical investigations of agates from Cordón de Lila, Chile." Andean Geology 42, 3 (2015) 386-396.

[8] Gonçalves, Bárbara Bellaver. "A quantum physics approach for simulating agate colors." (2012).

[9] Correia, S. L., G. Dienstmann, M. V. Folgueras, and A. M. Segadaes. "Effect of quartz sand replacement by agate rejects in triaxial porcelain." Hazardous materials 163, 1 (2009) 315-322.

[10] Götze, J., M. Plötze, H. Fuchs, and D. Habermann. "Defect structure and luminescence behaviour of agateresults of electron paramagnetic resonance (EPR) and cathodoluminescence (CL) studies." Mineralogical Magazine 63, 2 (1999) 149-163.

[11] Dake, H.C., F. L. Fleener, and B. H. Wilson. "Quartz family minerals." A handbook for the mineral collector (1938).

[12] http://rocktumbler.com/blog/what is agate jasper chalcedony//

[13] Driscoll, J. E. "A Study on the Origin of Banded Agate." (1938).

[14] Moxon, T., D. R. Nelson, and M. Zhang. "Agate recrystallisation: evidence from samples found in Archaean and Proterozoic host rocks, Western Australia." Australian Journal of Earth Sciences 53, 2 (2006) 235-248.

[15] Dumanska-S. M, L. N. Nowak, A. W. Birczynska, A. Gawel, M. Lankosz, and P.Wróbel. "Agates from Sidi Rahal, in the Atlas Mountains of Morocco: Gemological characteristics and proposed origin." Gems \& Gemology 49 (2013) 148-159.

[16] Gotze, J., M. Robert, V. Torsten, M.Axel, "Origin and geochemistry of agates in Permian volcanic rocks of the sub-Erzgebirge basin, Saxony (Germany).” Chemical Geology (2016).

[17] Hajalilou, B., and K. B. Vosug. "Geological and Gemological properties in Miyaneh agates (east Azerbaijan province)." (2008) 20-38.

[18] Jens G., W. Schrön, R. Möckel, K. Heide "The role of fluids in the formation of agates." Chemie der erde 72 (2012) 283-286

[19] Paul H. "Agate creek agate Australian gemologist."19 (1996) 215-220

[20] Devouard, B., and F.Notari. "The identification of faceted gemstones: From the naked eye to laboratory techniques." Elements 5, 3 (2009) 163-168.

[21] Sikorska, M., J. A. Rzymełka, A. Łoboda, and A. Gaweł. "Mineralogical and geochemical characterization of the "bituminous" agates from Nowy Kościół (Lower Silesia, Poland)." (2008). 
Spectroscopic Studies on Natural Gem- Agate in Sedimentary and Volcanic Host Rocks from (Bellesa, Addis Zemen and Bure), in Amhara National Regional State (Ethiopia)

[22] Beaster, T. J. "Agates: a literature review and Electron Backscatter Diffraction study of Lake Superior agates." PhD diss., BA thesis, Carleton College, (2005).

[23] Thomas, Arthur "Gemstones: properties, identification and use." (2008).

[24] Pearl, Richard "How to know the minerals and rocks." (1955).

[25] Henry Carl Dake "a handbook for the mineral collector" journal of Quartz family minerals (1938).

[26] Schumann, Walter. "Gemstones of the World." Sterling Publishing Company, Inc (2009)

[27] Dorothy M. Schlegel "Gemstones of the united states" contribution to economic geology (2011) 203-253

[28] Indira Bhavan "Civil Lines, Indian minerals" journal of quartz and other mineral (2015)

[29] Dorothy M. Schlegel "Gemstones of the united states" contribution to economic geology (2011) 203-253

[30] Shah, Raabell. "The analysis of natural gemstones and their synthetic counterparts using analytical spectroscopy methods." (2012).

[31] Mockel, R., J. Götze, S. A. Sergeev, I. N. Kapitonov, E. V. Adamskaya, N. A. Goltsin, and T. Vennemann. "Trace-element analysis by laser ablation inductively coupled plasma mass spectrometry (LA-ICP-MS): a case study for agates from Nowy Kościoł, Poland." 2, 2 (2009) 123-138

[32] Paralı, L., J. Garcia Guinea, R. Kibar, A. Cetin, and N. Can. "Luminescence behaviour and Raman characterization of dendritic agate in the Dereyalak village (Eskişehir), Turkey." Journal of Luminescence 131, 1 (2011) 2317-2324.

[33] Lee, DAVID R. "Characterisation of silica minerals in a banded agate: implications for agate genesis and growth mechanisms." (2007).

[34] Hatipoglu, M., Y. Tuncer, R. Kibar, A. Çetin, T. Karalı, and N. Can. "Thermal properties of gem-quality moganite-rich blue chalcedony." Physica B: Condensed Matter 405, 22 (2010) 4627-4633.

[35] Parthasarathy, G., A.C. Kunwar, and R. Srinivasan. "Occurrence of moganite-rich chalcedony in Deccan flood basalts, Killari, Maharashtra, India." European Journal of Mineralogy 13, 1 (2001) 127-134.

[36] Hatipoğlu, M., D. Ajò, and M. S. Kırıkoğlu. "Cathodoluminescence (CL) features of the Anatolian agates, hydrothermally deposited in different volcanic hosts from Turkey." Journal of Luminescence 131, 6 (2011) 1131-1139.

[37] Götze, J., M. Tichomirowa, H. Fuchs, J. Pilot, and Z. D. Sharp. "Geochemistry of agates: a trace element and stable isotope study." Chemical Geology 175, 3 (2001) 523-541.

Citation: Meselu Eskezia, et.al, "Spectroscopic Studies on Natural Gem- Agate in Sedimentary and Volcanic Host Rocks from (Bellesa, Addis Zemen and Bure), in Amhara National Regional State (Ethiopia)", International Journal of Advanced Research in Chemical Science, 7(7), pp. 13-26. DOI: https:// doi.org/10.20431/2349-0403.0707002

Copyright: () 2020 Authors, this is an open-access article distributed under the terms of the Creative Commons Attribution License, which permits unrestricted use, distribution, and reproduction in any medium, provided the original author and source are credited. 